\title{
AUTHENTIC MOVEMENT, GROUPS AND PSYCHOTHERAPY
}

Helen Payne, PhD

\subsubsection{2}

(Published in Self and Society - Forum for Contemporary Psychology, Summer 2003, vol 31, number 2, pages 32-36).

\section{INTRODUCTION}

Authentic Movement excited me when I discovered its powerful way of speaking to me within an empathic, non-judgmental and non-interpretative framework.

Authentic Movement is a newly emerging discipline of kinetic meditation through which the participant can learn to engage with a direct experience of herself, the group and the transpersonal. This is an experience beyond words and concepts. It can assist in developing body awareness, and body-mind-spirit connections. By gaining access and giving creative expression to inner worlds the invisible becomes visible or 'authentic' as Californian founder Mary Starkes Whitehouse (1979) claims.

Originally termed Movement-in-Depth by Whitehouse in the 1970's the method grew from its roots in dance and Jungian thought, mystical practice and pioneering work in dance movement therapy (Frantz 1972). Building on Jung's method of active imagination (Jung 1968) symbolic meaning is seen in physical expression.

Authentic Movement is not a set of exercises, creative movement (Payne 1990) or dance movement therapy (Payne 1992), although it may contribute to the latter (Musicant 2001). In Authentic Movement thought often stops. Normally there is 
no plan or intention to organise the movement as in improvisation for choreography. It is a completely self-directed approach in which participants may discover a movement pathway that offers a bridge between the conscious and the unconscious and between the group, the individual and the universal. It is the movement form of Active Imagination, and is particularly powerful because one moves before one knows it, as in the experiences referred to as 'I am moved'. Its uniqueness lies in the way movement is ephemeral, like a dream, it cannot be held onto, pinned down or repeated exactly. Nor can it be easily edited or stopped as in writing or language for example.

It has some similarity to group analysis in the way the conductor waits without overt action/participation, empathetically facilitating through verbal communication and presence to the group, and individual participants at times. The relationship between participants including the conductor are made clear and patterns begin to emerge. In Authentic Movement relationships of movers with other movers, witnesses with witnesses, and movers with witnesses provides opportunities for raising awareness of group held issues and differing parts of the group. In this way individuals come face to face with their projections.

\section{MOVERS AND WITNESSES}

In exploring the relationship between a mover and a witness, being seen and seeing, the hidden becomes visible from a connection between perspectives. Sometimes this meeting moment becomes a 'unitive experience' (Adler 1999) as the internal witness within each evolves. With eyes closed, and in the presence of 
one or many witnesses on the edge of the circle, the mover listens inwardly to find a movement arising from a cellular impulse.

To begin with the mover may feel they did not know what they were doing, similar to the experience of unconscious non-duality (Horrocks 2002). Day dreaming is also a non-ego-controlled experience, in which the mind lets go of the separateness normally experienced between the self and other.

Authentic Movement however is more frequently like lucid dreaming where there is interplay between the dreamer and the dreamed. The creativity is in the interplay. It can also connect the mover to the numinous, the universal 'I' or 'big me' rarely found in everyday life. In this experience the freedom from/loss of ego or 'little i' with attachments such as personal history, identity and so on enable a greater connection with the collective body (Adler 1999).

Although the witness has chosen not to move she is not a watcher or an observer of the mover, but an empathic and receptive external part of the mover. From this co-creation of reality results safety and a deep respect for each other. The witness acts in the role of container for the mover's immersion in unconscious material. After being seen clearly by a witness the mover begins to see herself and her witness can develop further. The witness after seeing another discovers a new ability to see herself. From these experiences both self-witnessing and ways of 'being' in relationship, in the here and now, are learned.

The witness engages in a process of somatic indwelling or waiting (Musicant 
1994), containing her projections and impulse to move, with the intention of feeling what it may be like for that mover, without preconceived ideas. This is akin to aspects of humanistic therapies; for example, Rogers (1957) stressed the role of empathy and unconditional positive regard as necessary and sufficient conditions for therapeutic change. A deep respect for self and others grows out of the process whereby an internal locus of control is fostered, each person being all that is right and true for them.

As the internal witness develops the mover often returns after the 'dream-state' to recall, in the presence of a witness, a significant event in the movement. This is a conscious experience (conscious non-duality) because it has been remembered. The non -dual experience is both subjective and objective at the same time; both knowing and not knowing; doing and not doing. Although the emphasis is on the 'here and now', recalling an event from the movement experience can add another dimension when shared verbally with witnesses. If witnesses saw the event described, the mover may then request they share their experiences. As an example I offer below one of my experiences as a witness:

"I saw a windmill, its sails turning in a wind. The base was firmly in the ground and held in place by a root or chain or some sort. I felt I was a mediator between the sky and the earth, a connector.” In speaking of an embodied event the mover may describe the movement together with associated feelings, sensations, images, body-felt senses, and thoughts. Drawing and creative writing may also be used to bring form and meaning to the experiences. Witnesses, by owning their experience, their projections, 
interpretations and judgements, give space to the mover to accept or reject their perceptions.

\section{THE COLLECTIVE BODY}

Moving, witnessing and sharing can enable connections between the individual, the group and the collective/universal body. For example, archetypal beings/figures may be seen, which have lived throughout time (such as Magician, Priestess, King, Grim Reaper, Jester, Warrior or Shaman), and which are lived again in the mover or witness or both. They are reborn through embodied participants. They can provide a link from the personal to the collective body giving images from which to give meaning to individual lives and communities.

The stimuli in our environment such as movers' contact with others or birds singing can have a deep presence inside the mover/witness as if they are part of them. Participants can become at one with their direct experience and feel no separation between themselves and aspects in their imagination or the environment. They experience unity and compassion when personal themes manifest out of, and connect to, a collective body of matter as each mover speaks and receives witnessing in the group.

This altered reality experience may help participants to make sense of life and personal themes. Spiritual questions may be explored at the same time as group dynamics. For example, during the breathing circle (one group structure) if movers leave and the space to return to the circle of witnesses the 
centre becomes empty once again, as in the beginning. Contemplation of this space can bring up, for example, issues of loss, enrichment, mortality, birth and re-birth. Everything and nothing is in the space at the same time and all participants surrender to this. These issues may be processed in the large group, or in two groups of movers and witnesses.

The concept of the 'wise observer/higher self' (Rowan 1993) in transpersonal psychotherapy is also relevant. For instance, by waiting for, and listening to, an inner prompt the mover rediscovers a consciousness of the 'wise observer'. By 'seeing' the mover clearly the witness regains a similar consciousness. I have discussed elsewhere (Payne 2001) the links between the process of witnessing in authentic movement and the internal supervisor as portrayed by Casement (1985 and 1990) in clinical supervision.

The Authentic Movement experience can be compelling and awesome. It draws participants from a range of backgrounds including the arts, caring/helping professions, and psychotherapy. Untrained movers are at an advantage over dancers who may need to unlearn technique. The non-judgemental environment promotes a safe, warm climate for moving in the presence of others. It is a good way to re-energise and make timeless, deeper connections with others.

\section{REFERENCES}

Adler, J (1999) The Collective Body. In: P. Pallaro (ed) Authentic Movement. London: Jessica Kingsley publishers. 
Frantz (1972) An approach to the centre: an interview with Mary Whitehouse.

Psychological Perspectives, 3, 1

Casement, P (1985) On learning from the patient. London; Routledge.

Casement, P (1990) On further learning from the patient. London: Routledge

Horrocks, R (2002) Non-Duality. Self and Society, 29, 6, 7-14.

Jung, CG (1968) Analytical Psychology: Its theory and practice. New York: Random House.

Musicant, S (1994) Authentic movement and dance therapy. American Journal of dance Therapy, 16, 2, Winter, 91-106.

Musicant, S (2001) Authentic movement: clinical considerations. American Journal of Dance Therapy, 23, 1, Spring, 17-26.

Payne, HL (1990) Creative movement and dance in groupwork. Oxon: Winslow press

Payne, HL (1992) Dance movement therapy: Theory and practice. London: Routledge.

Payne, HL (2001) Authentic movement and supervision. Emotion, ADMT.UK Newsletter, Winter, 13, 4.

Rogers, C (1957) The necessary and sufficient conditions for therapeutic personality change. Journal of Consulting Psychology, 21, 2, 95-103.

Rowan, J (1993) The transpersonal: psychotherapy and counselling. London: Routledge.

Whitehouse, MS (1979) Jung and dance therapy: two major principles. In: P. Bernstein (ed) Eight theoretical approaches to dance movement therapy, Iowa:Kendall/Hunt.

Please note the terms her/herself have been used whilst recognising that participants are of both genders.

Words 1,700

\section{BIOGRAPHY}

Dr Helen Payne is a UKCP accredited psychotherapist (AHPP), Fellow and Senior Registered dance movement therapist. For over 25 years she has pioneered the development of DMT in the UK starting the professional association, first training, research and publications. She has a private practice and is a Reader in Counselling and Psychotherapy at the University of Hertfordshire where she supervises a number of $\mathrm{PhD}$ 
candidates. She trained in Person-Centered Counselling and Group Analysis and has been developing her own form of Authentic Movement with groups and individuals for 12 years.. 